\title{
Aproximación a los problemas jurídicos estructurales de la Constitución
}

\author{
An approach to the legal structural problems of the \\ Constitution \\ Recibido: 3 de octubre de 2008 - Revisado: 19 de octubre de 2008 - Aceptado: 1 de noviembre de 2008
}

Julieta Arenas Ceballos*

Luis Javier Moreno Ortiz**

Universidad Sergio Arboleda, Bogotá, Colombia

\section{Resumen}

El análisis de la Constitución Política de Colombia como fuente de derecho, puede hacerse a partir de la consideración de cuatro problemas jurídicos estructurales: el normativo, el epistemológico, el lógico y el hermenéutico. Estos problemas pueden plantearse, respectivamente, de la siguiente manera: ¿la Constitución es fuente de derecho aplicable?, ¿la Constitución tiene un contenido determinado o determinable?, ¿la Constitución es la norma de prevalente en el sistema jurídico? y ¿cómo se interpreta la Constitución y cuál es el valor como fuente de dicha interpretación? Para estudiarlos es necesario tener en cuenta fenómenos como la crisis de la ley, el bloque de constitucionalidad, los derechos fundamentales innominados, los derechos humanos, el precedente y las líneas jurisprudenciales, de los cuales se ha ocupado con prolijidad la jurisprudencia de la Corte Constitucional. Realizar una aproximación intelectual verosímil y científicamente verificable a la existencia, consistencia, implicaciones e hipótesis de solución de los anteriores problemas, a partir de la jurisprudencia de la Corte Constitucional, es la sujeta materia de este escrito.

\section{Palabras clave}

Constitución política. Derecho constitucional. Interpretación constitucional. Supremacía de la Constitución.

\footnotetext{
Abstract

The analysis of the Colombian Constitution as a source of law can be made after consideration of four legal structural problems: norms, epistemology, logics, and hermeneutics. These problems may be stated as follows: Is the Constitution a source of applicable law? Does the Constitution have a determined or determinable content? Is the Constitution the prevalent norm in the legal system?, and, how is the Constitution interpreted and what is the value of this interpretation as a source? To study them, phenomena such as the crisis in Law, the constitutionality block, the fundamental rights, the human rights, preceding laws and jurisprudential lines must be taken into account. All of these have been duly addressed by the Constitutional Court's jurisprudence. The goal of this essay is to perform an intellectual, truthful and scientifically verifiable approach to the existence, coexistence, implications and solution hypotheses to the aforementioned problems, from the jurisprudence of the Constitutional Court.

Key words Constitution. Constitutional law. Constitutional interpretation. Supremacy of the Constitution.
}

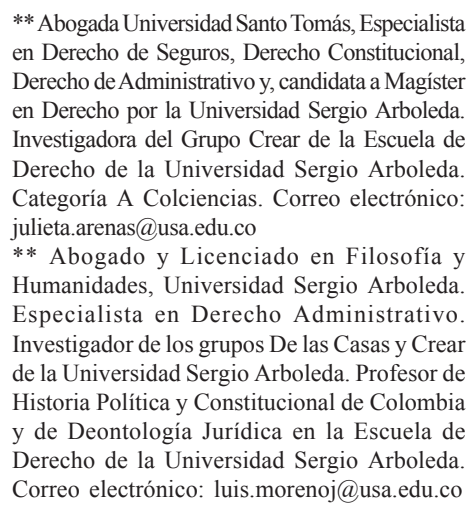

** Abogada Universidad Santo Tomás, Especialista en Derecho de Seguros, Derecho Constitucional, Derecho de Administrativo y, candidata a Magíster en Derecho por la Universidad Sergio Arboleda. Investigadora del Grupo Crear de la Escuela de Derecho de la Universidad Sergio Arboleda. Categoría A Colciencias. Correo electrónico: julieta.arenas@usa.edu.co

** Abogado y Licenciado en Filosofía y Humanidades, Universidad Sergio Arboleda. Especialista en Derecho Administrativo. Investigador de los grupos De las Casas y Crear de la Universidad Sergio Arboleda. Profesor de Historia Política y Constitucional de Colombia y de Deontología Jurídica en la Escuela de Derecho de la Universidad Sergio Arboleda. Correo electrónico: luis.morenoj@usa.edu.co 
No existe la casualidad, y lo que se nos presenta como azar surge de las fuentes más profundas. Johann Christoph Friedrich von Schiller.

\section{Introducción}

La disciplina jurídica ha experimentado notables cambios en los últimos siglos. Esos cambios han ocurrido en su mayoría merced a la institución jurídica de la Constitución, la cual amerita ser situada, así sea muy someramente, dentro del contexto histórico inmediato. El más reciente renacimiento del constitucionalismo, iniciado en Inglaterra en el siglo XVII, con la "gloriosa revolución", que con el bill of rights, profundiza la tradición iniciada por la carta magna, acaece principalmente en el siglo XVIII con la revolución norteamericana y con la revolución francesa. En estas revoluciones ocupa un lugar principal un documento escrito denominado Constitución. Estas primeras constituciones, como hijas que son de unas revoluciones emancipadoras, de la monarquía inglesa en el caso americano y de la monarquía y la nobleza en el francés, tienen como núcleo central la libertad, son revoluciones liberales. Esta libertad se estructura en términos jurídicos sobre la base del derecho. Así, pues, la revolución liberal encuentra su contrapartida en el Estado de Derecho.

El siglo XIX, en medio de los coletazos de la revolución industrial e imbuido hasta los tuétanos de la noción de progreso, va ha servir de escenario para el surgimiento y consolidación de una visión social del derecho, que se concretará en el movimiento socialista, primero utópico y más tarde científico. Esta particular visión se encausará dentro de una nueva revolución, la revolución social, que tendrá como núcleo central la igualdad. Su huella aparece claramente visible en el siglo XIX y durante gran parte del siglo XX. La revolución social encuentra su contrapartida en el Estado Social.

El siglo XXI, luego de la experiencia cruenta de las tres grandes guerras: la primera, la segunda y la fría, buscará un equilibrio entre libertad, igualdad y democracia. La contrapartida de esta búsqueda, aún incipiente, parece ser el Estado Constitucional. La Constitución, a más de servir de eje en el proceso histórico señalado, se convierte en el referente fundamental y aglutinante dentro del Estado Constitucional. Es un referente fundamental porque brinda fundamento a los derechos, a las libertades y a la organización de cada Estado. Es aglutinante, porque todo tiende a converger hacia ella por diversas vías. Basta mirar la importancia creciente de fenómenos como los derechos fundamentales y la constitucionalización del derecho, para advertirlo.

\section{Alcance}

Este ensayo pretende realizar una aproximación intelectual verosímil y científicamente verificable, a partir de la jurisprudencia de la Corte Constitucional, al fenómeno de la Constitución Política de Colombia, en tanto norma jurídica, desde la perspectiva de las fuentes del derecho.

\section{Fuentes}

Las fuentes de este escrito son de tres clases: normativas, jurisprudenciales y doctrinales. Dentro de la primera clase se destacan la Constitución Política de Colombia y algunos tratados internacionales; en la segunda aparece la jurisprudencia de la Corte Constitucional; en la tercera se encuentra una serie de referencias bibliográficas a la doctrina nacional y extranjera.

\section{Metodología}

Esta aproximación, soportada en un análisis del contenido normativo de la Constitución, se hará a partir del planteamiento preliminar de algunas cuestiones, las cuales irán seguidas de una posible hipótesis de respuesta. En ambos planteamientos: el problemático y el hipotético, y en cada caso, se procurará determinar con precisión el fundamento normativo y el desarrollo argumentativo. En este documento se hará uso de dos métodos: el analítico para plantear las cuestiones y las hipótesis, y para precisar su fundamento y desarrollo, y el de falsación, propuesto por Popper (1994), para verificar por medio de contraejemplos su verosimilitud. 


\section{Problemas planteados}

A partir del análisis de la Constitución Política de Colombia es posible plantear cuatro problemas jurídicos estructurales, que son: el normativo, el epistemológico, el lógico y el hermenéutico. Estos problemas pueden presentarse conforme a las siguientes cuestiones: ¿la Constitución es fuente de derecho aplicable?, ¿la Constitución tiene un contenido determinado o determinable?, ¿la Constitución es la norma de prevalente en el sistema jurídico?, y ¿cómo se interpreta la Constitución y cuál es el valor como fuente de dicha interpretación? Estos problemas principales serán abordados a partir del análisis de algunos problemas secundarios, planteados a partir de fenómenos como: la crisis de la ley, el bloque de constitucionalidad, los derechos fundamentales innominados, los derechos humanos, el precedente y las líneas jurisprudenciales.

\section{Hipótesis}

Los anteriores problemas generan al menos dos hipótesis contrapuestas de solución. Si bien una de ellas resultará a la postre invalidada por el proceso dialéctico de falsación, la supervivencia de la otra sólo implica su verosimilitud, es decir, su aceptación provisional hasta tanto aparezca evidencia de su falsabilidad. No se trata, entonces, de sostener la validez incondicional, basada en certeza, de ninguna hipótesis, a modo de dogma, a partir del cual desarrollar una dogmática. Se trata de buscar la hipótesis de trabajo que resista la prueba de falsación, que aparezca como razonable y que pueda servir como fundamento para buscar una solución adecuada a los problemas planteados.

La cuestión de si ¿la Constitución es fuente de derecho aplicable?, puede ser respondida de dos maneras: afirmativamente o negativamente. La respuesta depende de si la Constitución es o no una verdadera norma jurídica. Si la Constitución no tiene un contenido normativo, sino meramente programático, valga decir, si es apenas un proyecto político de lo que una sociedad quisiera llegar a ser, es evidente que ella no puede ser fuente de derecho (hipótesis A). Si la Constitución sí tiene contenido normativo, es decir, si es una norma jurídica, ella es fuente de derecho (hipótesis B).

La cuestión de si ¿la Constitución tiene un contenido determinado o determinable?, admite tres posibles respuestas: tiene un contenido determinado, tiene un contenido indeterminado pero determinable, o tiene un contenido indeterminado e indeterminable. La respuesta depende de qué es la Constitución, o mejor de cuáles son las normas constitucionales. Si todas las normas constitucionales están en la Constitución, a lo largo y ancho de sus más de trescientos ochenta artículos, y de sus múltiples reformas, su contenido está determinado (hipótesis C). Si las normas constitucionales no están sólo en la Constitución, sino también en otras normas, tales como los tratados internacionales de derechos humanos no restringibles en estados de excepción, su contenido, si bien no está determinado prima facie, es determinable realizando una integración sistemática entre la Constitución y esos tratados (hipótesis D). Si las normas constitucionales no están sólo en la Constitución ni en los tratados internacionales de derechos humanos, sino en otros tratados, o en otros documentos internacionales que no son tratados, verbi gracia: recomendaciones, estudios, opiniones, resoluciones, o incluso en referentes no escritos, como los derechos fundamentales innominados, el contenido de la Constitución no está determinado, ni es determinable a priori, pues siempre quedará alguna o algunas normas constitucionales en la zona de penumbra, de la cual sólo podrán salir en la medida en que el tiempo y las demás circunstancias lo propicien y permitan (hipótesis E).

La cuestión de si ¿la Constitución es la norma de prevalente en el sistema jurídico?, permite plantear dos respuestas: la afirmativa y la negativa. La respuesta depende de cuál sea el rango y la jerarquía de la Constitución. Si se considera que la Constitución es norma de normas, es decir, 
fundamento de todas las demás normas, se hace evidente que ella es la norma prevalente dentro del sistema jurídico (hipótesis F), lo que tiene tres importantes implicaciones: que todas las demás normas deben ser conforme a su mandato, so pena de inexequibilidad o de nulidad, o en general de su invalidez; que dichas normas deben ser siempre interpretadas y aplicadas conforme a la Constitución; y que en caso de incompatibilidad entre alguna de ellas y la Constitución, se aplicará preferentemente esta última. Tanto si se considera que la Constitución no es norma jurídica, como si se considera que existe una norma distinta a la Constitución que sobre ella prevalece, verbi gracia, un tratado internacional, la respuesta a la cuestión debe ser negativa (hipótesis G). Si esta hipótesis llegase a ser verosímil, las implicaciones destacadas en la hipótesis anterior, serían predicables de esa norma prevalente.

La compleja cuestión de ¿cómo interpreta la Constitución la Corte Constitucional y cuál es el valor como fuente de dicha interpretación?, especialmente en cuanto atañe al punto del valor de la interpretación, debe matizarse según del asunto de que se trate, y tiene tres posibles respuestas: valor normativo, valor ilustrativo, o no tiene valor. La respuesta depende de cuáles son los efectos jurídicos de la interpretación de la Constitución. Antes de plantear las hipótesis en este caso, es menester señalar la diferencia que existe entre decisum, ratio decidendi y obiter dicta dentro de la estructura de una sentencia, para precisar que la cuestión se plantea respecto de la ratio decidendi y no del decisum o de los obiter dicta, tanto en el caso de las sentencias de constitucionalidad como en el caso de las sentencias de tutela. En la primera respuesta a la cuestión, la interpretación de la Constitución tiene valor normativo como fuente de derecho y debe ser considerada como tal por todos los operadores jurídicos (hipótesis H). En la segunda respuesta, la interpretación de la Constitución es una guía auxiliar no vinculante para los operadores jurídicos, que tiene el mero propósito de ilustrar (hipótesis I). En la tercera respuesta, la interpretación no tiene ninguna trascendencia ni valor, pues, a más de no tener carácter normativo, está confinada al estrecho cerco de un caso histórico, irrelevante para quienes no han hecho parte de él y para el decurso histórico, y carente de valor, por cuanto los operadores jurídicos deben asumir por su propia cuenta y riesgo, partiendo solamente de su propio criterio, la tarea de interpretar las normas jurídicas aplicables (hipótesis J).

\section{El problema normativo}

\section{La norma de las normas}

La cuestión de si ¿la Constitución una verdadera norma jurídica?, crucial para este asunto, suele contribuir a distinguir dos grupos de opinión. El primero de ellos, más cercano a disciplinas distintas al derecho constitucional, tradicionalmente empeñado en defender una autonomía científica, generalmente afincada en el sistema legal codificado, ha sido reacio a reconocer a la Constitución la condición de norma jurídica. Según esta opinión la Constitución es una carta de navegación, útil para trazar el camino de las instituciones, para definir programas de lo que debe hacerse, pero que carece de la condición de fuente del derecho, pues ella no puede aplicarse a casos concretos, sino que está reservada para los debates abstractos (hipótesis A). El segundo grupo, quizá desde una perspectiva más integradora de las distintas disciplinas jurídicas, es proclive a sostener tanto que la Constitución es una norma jurídica como las consecuencias que de ello se siguen (hipótesis B).

La hipótesis A suele fundarse por sus defensores en el artículo 230 de la Carta, en el cual parecería definirse cuáles son las fuentes de derecho que deben consultar los jueces para decidir sus casos. Entre esas fuentes no se menciona la Constitución. Por el contrario, la fuente principal es la ley. La hipótesis B se funda en el artículo 4 de la Carta, que define a la Constitución como "norma de normas". En este artículo también se ordena la aplicación preferente en la práctica de la Constitución frente a la ley u 
otra norma jurídica en caso de incompatibilidad. El contenido del artículo 4 de la Constitución de 1991 reproduce lo establecido en su debida oportunidad por el acto legislativo número 3 de 1910, reformatorio de la Constitución de 1886.

Al someter la hipótesis A al proceso de verificación mediante contraejemplo, dentro del contexto de la jurisprudencia de la Corte Constitucional, se aprecia que la Constitución sí ha sido considerada y aplicada como norma jurídica, entre otras en las sentencias: T-006, C-406, C-421 y C-434 de 1992; C-131, C-531 de 1993; C-511 de 1994; T-063, C-069 de 1995; T-318 de 1997; T067, SU-253, T-329, C-400 y C-600 de 1998; C273, C-582 de 1999; C-037, C-562 de 2000; C-739 de 2001; C-452, C-644 de 2002; C-207, C-741 de 2003; C-311 de 2004; C-1040 de 2005; C-398, T845 de 2006. Sobre la base de esta evidencia, es posible señalar que la hipótesis A es falsa.

La jurisprudencia constitucional reconoce a la Constitución como norma jurídica, y lo que no es menos importante: la aplica en casos reales, refrendando la hipótesis B. No obstante, es menester anotar que aún existe resistencia, aunque cada vez menor, a aplicar la Constitución como norma. Este fenómeno se puede apreciar respecto de algunos derechos por ella reconocidos, como los derechos sociales, cuya condición de fundamentales y cuyo contenido imperativo, todavía siguen siendo materia de disputa. Dejando de lado en esta oportunidad el debate sobre si son o no fundamentales, suficientemente ilustrado por Arango (2005), vale la pena destacar que alguna parte de la opinión se inclina por considerar que tales derechos tienen un contenido meramente programático, lo que implica su desarrollo gradual, conforme a las circunstancias y, por tanto, su no exigibilidad judicial. La opinión contraria, más próxima a la hipótesis $\mathrm{B}$, reclama que esos derechos tienen un contenido normativo, base sobre la cual se sustenta su exigibilidad por la vía judicial.

Si la Constitución es una norma jurídica, ella debe ser hecha en serio, como lo advierte Dworkin
(1995), pues sus mandatos no están solamente escritos en el papel, sino que tienen la capacidad de generar obligaciones jurídicas que deben ser cumplidas por los responsables y garantizadas por el sistema judicial.

\section{Visión tradicional de las fuentes}

La visión tradicional de las fuentes, en la modernidad, suele tener como principal punto de referencia a la ley, de tal suerte que se llega a considerar al legislador como el hacedor del derecho, al gobierno como su ejecutor y a los jueces como sus aplicadores. El Estado de Derecho se equipara al imperio de la ley. El oficio de juzgar se hace mecánico, serial; opera conforme a un método deductivo, según un silogismo formal, que parte de la regla contenida en la ley, pasa por el caso y concluye con la sentencia. Dentro de este contexto la Constitución, con su carga de principios y valores, y sus consiguientes efectos no mecánicos sino dialécticos, aparece como un elemento distorsionador.

El positivismo y el formalismo son verdaderos hábitos intelectuales, algunos dirán virtudes, otros vicios, aún encarnados con fuerza en la disciplina jurídica, que corresponden a esa cosmovisión. López (1999, 2004, 2006 y 2007) analiza con prolijidad los fundamentos, el desarrollo y las consecuencias de la visión tradicional de las fuentes. El contraste entre la visión tradicional y la visión no tradicional, puede apreciarse con provecho en textos como los de Bobbio (1992, 2001), Kelsen (1997, 2001), Ihering (1954 y 1962), Gény (1925), Josserand (1982), Pound (1942), Hart (1961), Ross (2007), Recasens (1956) y Dworkin(1995).

Un vestigio de la manera tradicional de comprender las cosas se encuentra en el mencionado artículo 230 de la Carta. Esto es apenas normal, pues las tradiciones no cambian de la noche a la mañana. Por el contrario, las tradiciones luchan por asegurar su continuidad, así para lograrlo deban empeñarse en la defensa de auténticos dogmas de fe. Si bien antes de la 
Constitución de 1991 existía también la otra visión, la correlación de fuerzas en el combate dialéctico, que antes le había sido favorable a la visión tradicional, ha comenzado a serle desfavorable, como puede apreciarse con claridad en las sentencias C-113 y C-131 de 1993, C-083, T123 y T-260 de 1995, de la Corte Constitucional. Este conflicto de visiones, caracterizado con ligereza por algunos como la pugna entre el viejo derecho y el nuevo derecho, o en el tema jurisdiccional como el "choque de trenes", forma parte del complejo fenómeno de la crisis de las fuentes del derecho que subyace en el desplazamiento que sufre la ley y el correlativo emplazamiento de la Constitución Política.

\section{La crisis de la ley}

La aparición del Estado Constitucional ha significado la valorización de la Constitución y la devaluación de la ley. La ley antaño tan poderosa y magnífica, verdadero señor del derecho, es hogaño más limitada y humilde, se ha convertido en vasallo de un nuevo señor: la Constitución. El otrora imperio de la ley ha sido reemplazado por el imperio del derecho. El imperio del derecho no es orden totalitario. El derecho no es sólo la Constitución, o mejor: la Constitución no es todo el derecho, pues además existen otras muchas normas tanto en el plano internacional como en el nacional, que forman parte de este imperio, entre las cuales ocupa un lugar distinguido la ley.

La condición de fuente principal, que usualmente detentaba la ley parece ser, entonces, un hecho superado por la Constitución. La fuerza normativa de la Carta funciona en un Estado democrático, según Bidart (1995), de dos maneras: la objetiva y la subjetiva. Conforme a la primera, las normas constitucionales "dan origen y presiden un ordenamiento jurídico que queda embebido de su núcleo o contenido esencial". Conforme a la segunda, "los derechos, libertades y garantías de su plexo confieren a cada persona el status jurídico-político subjetivo que la emplaza en la comunidad estatal de acuerdo a su dignidad". La crisis de la ley aparece retratada con contundencia en este estudio de Bidart y, entre otros muchos, en los de De Otto (1999), Martín-Retortillo (2004), Echeverri (2006) y Ross (2007).

\section{El problema epistemológico}

Enfrentarse, siempre enfrentarse, es el modo de resolver el problema. ¡Enfrentarse a él! Joseph Conrad.

\section{Las normas constitucionales}

No todo el derecho está en la Constitución, pero toda la Constitución sí está en el derecho. Esta consecuencia se sigue de que la Constitución sea norma jurídica. De la misma manera, y analizando ahora el asunto más en detalle, y partiendo de la base de que todas las normas que están en la Constitución son constitucionales, podría preguntarse si itodas las normas constitucionales están en la Constitución? La hipótesis $\mathrm{C}$ responde a esta crucial pregunta de manera afirmativa. Las hipótesis D y E, lo hacen de manera negativa.

Antes de iniciar el proceso de verificación de las hipótesis, es menester advertir que en un escrito anterior (Moreno, 2004), con ocasión de la reseña de una interesante obra de Sanin (2004) sobre la justicia constitucional, se había sostenido que la Constitución sí adolece de un problema epistemológico agudo, pues no todas las normas constitucionales están siquiera escritas, ya que algunas sólo aparecen como posibilidades latentes de realización; se había procurado elaborar un discurso que brindase sustento a ese aserto; y se había resaltado la importancia que tiene la hermenéutica constitucional, pues la vía interpretativa podía ser la idónea para dar sentido a los textos confusos y para concretar en cada caso y conforme a las circunstancias, aquellas normas constitucionales desconocidas. Por lo tanto, en este punto existe un antecedente relevante para el actual juicio, aunque, no sobra reiterarlo, en el presente documento se procurará verificar las hipótesis a partir de referentes 
objetivos externos que pueden ser coincidentes o no, con los juicios emitidos en otros documentos.

La hipótesis $\mathrm{C}$, que identifica a la Constitución con las normas constitucionales, parece ser prima facie incontrovertible. Se cae de su peso que las normas constitucionales se encuentren en la Constitución y no en alguna otra parte, pues a nadie se le ocurriría buscar por fuera de su texto, ya que se supone que la Constitución, como verdadero código político, lo contiene todo. Esta tendencia sistemática interna, tan cara a la codificación, de propugnar por reunir, organizar y armonizar todas las normas de una materia en un solo cuerpo, parece ser una exigencia insoslayable de la razón humana. Con todo, la propia Carta, principalmente en sus artículos 93 y 94, parece establecer, además de una coherencia sistemática interna, una integración y armonización sistemática externa, respecto de referentes distintos a la Constitución.

El artículo 93 ha servido de base a la jurisprudencia de la Corte Constitucional para sostener la existencia de un bloque de constitucionalidad, en virtud del cual, merced a una integración sistémica externa, se reconocen como normas constitucionales mandatos establecidos en tratados internacionales de derechos humanos. La Corte se ha referido al artículo 93, con ocasión del tema del bloque de constitucionalidad, entre otras, en las siguientes sentencias: T-402, T-426, C-574 de 1992; C-089 de 1994; C-225 de 1995; C-327 de 1997; C-030, C-256, C-400, SU-640 de 1998; T-483, C-582 de 1999; C-774 de 2001; C-067, T-558, T-719 de 2003; y T-1191 de 2004. El artículo 94, que establece lo que se ha dado en llamar "derechos fundamentales innominados", también ha sido empleado por la Corte, si bien con mayor timidez que en el caso del bloque de constitucionalidad, entre otras, en las sentencias: T-426 de 1992; C109, T-477 de 1995; T-263 de 1997; T-1103 de 2000; T-881 de 2002; T-719 de 2003; T-792 de 2004; T-934 de 2005; T-730 y T-821 de 2007. De lo anterior se sigue que existen normas constitucionales por fuera de la Constitución, en tratados internacionales de derechos humanos, como es el caso del bloque de constitucionalidad, o indeterminados por ella, e incluso fuera de cualquier texto, como ocurre derechos fundamentales innominados. En ambos casos, el supuesto racional al que se había aludido al exponer la hipótesis $\mathrm{C}$, y la misma hipótesis, son falsos. El proceso de verificación de las dos hipótesis restantes, requiere un análisis más detallado tanto del bloque de constitucionalidad como de los derechos fundamentales innominados, lo cual se hará en las siguientes secciones.

\section{El bloque de constitucionalidad}

El bloque de constitucionalidad es una herramienta sistemática que permite integrar al conjunto de las normas constitucionales algunos mandatos establecidos por fuera del texto de la Constitución, especialmente en tratados internacionales. Esta integración, como ocurría con la antigua proposición jurídica completa, de rigor en el recurso extraordinario de casación, justamente por ser una herramienta sistemática, debe ser construida a partir de las circunstancias del caso que se juzga y a partir de los referentes normativos relevantes. El bloque, como lo sostiene Uprimny (2001), apoyándose en varias sentencias de la Corte Constitucional, se construye a partir de las normas que tienen relevancia constitucional para decidir el asunto, de ahí que el bloque de constitucionalidad, siguiendo este razonamiento, tenga varias acepciones y que éstas se interrelacionen en la práctica. Las acepciones son tres: la de jerarquía constitucional, sentencia C225 de 1995; la de parámetro de constitucionalidad de leyes, sentencias C-578 de 1995 y C-135 de 1996; y la de parámetro para decidir casos constitucionales, sentencia C-477 de 1995.

El concepto de bloque de constitucionalidad es equívoco, pues tiene varios sentidos. Eso se debe a que no es un concepto estático, definido de antemano, sino que por el contrario, debe ser construido en cada caso. En rigor, el bloque de constitucionalidad siempre es un concepto ad hoc. Esta circunstancia plantea un elevado 
obstáculo a la pretensión, contenida en la hipótesis $\mathrm{D}$, de que las normas constitucionales son determinables a priori, como se verá con mayor detalle enseguida al estudiar algunas de sus aplicaciones en la práctica jurisprudencial y al tratar de comprenderlas con el auxilio de la doctrina.

Siguiendo la confusa opinión común, aunque paulatinamente va encontrando alguna claridad a partir de los prolijos estudios de Uprimny (2001), Fajardo (2007) y Romero (2008), se suele sostener que el bloque de constitucionalidad es una noción en cuyo fundamento convergen los artículos 9, 53, 93, 94, 101.2, 151, 152 y 214.2 de la Constitución. La principal consecuencia que se sigue de tal afirmación, evidente en la práctica, es que el bloque no está conformado solamente por los tratados internacionales de derechos humanos, de los que habla el artículo 93, y que sería la visión inicial del asunto, sino que dentro de él también encuentran cobijo los tratados de derecho internacional humanitario, como ocurre en las sentencias C-225 de 1995; C-206 de 1996; C-327 de 1997; SU-256, T-483, T-568 de 1999; C-010 de 2000; C-774 de 2001; C-067, T-719 de 2003; T-1191 de 2004; C-097, C-291 de 2007; los convenios, acuerdos o recomendaciones de la Organización Internacional de Trabajo, como se aprecia en las sentencias C-662 de 1997, T568 de 1999 y C-030 de 2008; los tratados internacionales de límites, como se nota en las sentencias C-225 de 1995, C-358 de 1997, C191 y C-400 de 1998, C-1022 de 1999 y C-067 de 2003; las leyes estatutarias, como puede verse en las sentencias C-578 de 1995, C-358 de 1997 y C-708 de 1999; y las leyes orgánicas, como aparece en las sentencias C-337 de 1993, C-423 y C-600 A de 1995 y C-281 de 1997.

Del discurso elaborado por la Corte Constitucional para justificar esta compleja aplicación práctica, merece destacarse la distinción que hace entre los tratados internacionales, para integrar sólo algunos de ellos al bloque de constitucionalidad, como se precisa en las sentencias C-358 de 1997, C-191 de 1998 y C-155 de 2007, pero salvaguardando en todo caso la importancia de todos los tratados internacionales, pues si bien no todos son referentes de constitucionalidad de ello no se sigue que carezcan de valor normativo, ya que al integrarse al ordenamiento jurídico son fuentes de derecho aplicables. Así lo sostiene la Corte en las sentencias C-492 de 1998, C-1144 de 2004, C-557 de 2005 y C-155 de 2007, y al ocuparse del principio pacta sunt servanda, en la sentencia C-400 de 1998, en desarrollo del principio de integración y armonización del derecho interno y del derecho internacional, propio de una visión sistémica externa, conforme a la convención de Viena sobre el derecho de los tratados entre Estados y Organizaciones Internacionales o entre Organizaciones Internacionales, del 21 del marzo de 1986, aprobada por la ley 406 de 1997. También merece una mención especial, la afirmación que hace la Corte de que los convenios, las decisiones y las recomendaciones de la Organización Internacional de Trabajo hacen parte del bloque de constitucionalidad, como en los casos resueltos por las sentencias C-662 de 1997, T-568 de 1999, C567 de 2000, T-606 de 2001, C-038 de 2004 y C030 de 2008.

En la práctica parece evidenciarse que no existe un solo bloque de constitucionalidad, sino tantos y tan complejos como lo requieran las circunstancias. Sin embargo, para verificar la hipótesis D, es menester considerar el bloque de constitucionalidad en su primera acepción, es decir: la de la jerarquía constitucional, aunque, como ya se advirtió siguiendo a Uprimny (2001), no es sencillo separar esta acepción de las otras dos. No obstante, de la jurisprudencia de la Corte, atrás estudiada, parece seguirse que no sólo hacen parte del bloque de constitucionalidad, en tanto normas de jerarquía constitucional, las contenidas en los tratados internacionales sobre derechos humanos que "reconocen los derechos humanos y que prohíben su limitación en los estados de excepción".

El tema del bloque de constitucionalidad hace evidente que la Constitución no puede ser comprendida ni empleada sin una teoría constitucional que permita aproximarse de manera 
coherente a ella, pues como lo advierte Chinchilla (1999), una teoría es indispensable para develar el sentido real de los artículos codificados, y la teoría constitucional es la única herramienta que permite superar las contradicciones internas, los vacíos y oscuridades de una Constitución.

\section{Los derechos fundamentales innominados}

El obstáculo para la verificación de la hipótesis $\mathrm{D}$, que el complejo fenómeno del bloque de constitucionalidad implica, si bien elevado, podría parecer a algunos que es superable con ciertas matizaciones. Empero, ese no es el más formidable enemigo con el que debe habérselas la hipótesis, pues es menester considerarla frente a los derechos fundamentales innominados.

El artículo 94 de la Carta pese a su inofensiva brevedad, es una verdadera mina de oro, que hasta ahora ha sido explotada tímida y cautamente por la Corte Constitucional, como se vislumbra en las sentencias T-426 de 1992, C-109 y T-477 de 1995, T-263 de 1997, T-1103 de 2000, T-881 de 2002, T719 de 2003, T-792 de 2004, T-934 de 2005, T730 y T-821 de 2007. Esta norma establece que los derechos establecidos por las normas constitucionales, se encuentren éstas en el texto de la Constitución, o en convenios internacionales vigentes, incorporados por medio de la herramienta del bloque de constitucionalidad, son apenas una enunciación, que no puede entenderse "como negación de otros que, siendo inherentes a la persona humana, no figuren expresamente en ellos".

La extensa y compleja enunciación de derechos, que está determinada en el caso de los que aparecen en el texto constitucional, y acaso puede ser determinable en cuanto atañe a los que aparecen en los tratados que se incorporen al bloque de constitucionalidad, al no ser taxativa, es indeterminable a priori respecto de los demás derechos inherentes a la persona humana, que ni siquiera han sido enunciados. Esa respuesta sólo se puede obtener con el tiempo, en la medida en que las circunstancias lo permitan. De momento la jurisprudencia de la
Corte, al hablar de estos derechos menciona palabras como dignidad y mínimo vital. Así, pues, la hipótesis D es falsa y, por los mismos motivos, la hipótesis E aparece como verosímil.

\section{El problema lógico.}

$$
\begin{array}{r}
\text { En la práctica, sólo es problema lo que la } \\
\text { inteligencia puede resolver. } \\
\text { Hermann Keyserling. }
\end{array}
$$

\section{Las exigencias del sistema jurídico}

El bloque de constitucionalidad, en cualquiera de sus acepciones, implica la necesidad sistémica de integrar normas relevantes para juzgar un caso. Esta integración no puede ocurrir de cualquier manera. La integración del bloque en la acepción de jerarquía constitucional requiere que todas las normas integradas tengan el mismo rango y jerarquía, aunque no necesariamente la misma fuente, que puede ser la propia Constitución, los tratados internacionales o la persona humana. $\mathrm{La}$ integración del bloque en su acepción de parámetro de constitucionalidad, si bien admite la integración de normas de diverso rango y jerarquía, y de diversa fuente, como pueden ser las normas constitucionales y las normas legales, especialmente las establecidas en leyes estatutarias u orgánicas, no admite normas de igual o inferior rango y jerarquía que aquella que se encuentra sub examine del juzgador de constitucionalidad. La integración del bloque en su acepción de parámetro para decidir casos constitucionales, quizá la más amplia de todas, admite la inclusión de muchos referentes, tanto normativos como no normativos, como pueden ser las recomendaciones o estudios de organismos internacionales. Las exigencias del sistema jurídico son más rigurosas para la integración en los dos primeros casos.

Las nociones de rango y jerarquía implican que las normas, lejos de ser iguales, como suele predicarse de los hombres, tienen una relación asimétrica, pues unas son el fundamento y el límite de otras, que en ningún evento pueden desconocer ese origen o transgredir esos linderos. 
Sobre este tema es de sobra conocida la jerarquía elaborada por Kelsen (1997, 2001), tan afín al positivismo, para estructurar el derecho positivo, a partir de la fundamentación de las normas. En este esquema no hay duda de que la norma primera, la fundamental, es la Constitución. No obstante, la integración del bloque de constitucionalidad, especialmente en su primera acepción, al irrumpir en el panorama con normas constitucionales que no están en la Constitución, sino en tratados internacionales, cuestiona esa radical certeza positivista y reclama un replanteamiento del tema.

\section{La cuestión de la prevalencia}

El artículo 93 de la Carta, además de servir de fundamento para la integración del bloque de constitucionalidad, establece su prevalencia en el orden interno. Este breve texto, pese a su aparente claridad, resulta ser en alto grado complejo, pues la Constitución también establece en su artículo 4, como se ha visto atrás, que ella es norma de normas. Sobre esta base se habla de su supremacía, valga decir, de su prevalencia en el orden interno. El problema de la prevalencia, que la propia Constitución plantea entre las normas de los tratados incorporados al bloque de constitucionalidad y las normas de la Constitución, no es sólo teórico, sino que puede implicar importantes consecuencias en la práctica. El interesante conflicto constitucional surgido con ocasión del proceso criminal que se sigue contra los altos funcionarios del Estado y las garantías judiciales a las que tienen derecho, ha generado una contraposición entre la Constitución y los tratados internacionales, que hasta ahora se ha eludido o se ha resuelto de manera ambivalente.

El problema de la prevalencia implica la negación de la equivalencia. Si las normas constitucionales de los tratados y las normas constitucionales de la Constitución tuviesen el mismo rango y jerarquía, el problema lógico, manifestado en su contradicción, no podría resolverse en el plano normativo, sino en el hermenéutico. Esta posibilidad se explorará en la siguiente sección.

Si se niega la equivalencia, valga decir, el igual rango y jerarquía entre las normas constitucionales, como parece insinuarlo el citado artículo 93, en caso de conflicto, es menester optar entre las siguientes alternativas: la prevalencia de las normas constitucionales contenidas en la Constitución (hipótesis F) o la prevalencia de las normas constitucionales contenidas en tratados internacionales incorporados en la Constitución (hipótesis G). La prevalencia implicará, entre otras consecuencias, que la norma que no prevalece deba ser interpretada conforme a la que sí lo hace.

La jurisprudencia de la Corte Constitucional en el conflicto atrás señalado es, por lo menos, ambigua. En una primera etapa histórica, planteado el tema de la prevalencia, la Corte, con la sentencia C-142 de 1993, hábilmente elude el problema, con la estrategia de negar que exista conflicto. Esa estrategia se mantiene, aduciendo la cosa juzgada en la sentencia C-411 de 1997.

En una segunda etapa, se reconoce la posibilidad del conflicto, pero trata de remediarse acudiendo a la hermenéutica, interpretando de una parte que el principio de la doble instancia, establecido por un tratado internacional que hace parte del bloque, no es absoluto, como se sostiene en la sentencia C-561 de 1996, y de otra que el principio de la libre configuración del legislador, establecido por la Constitución, tampoco es absoluto, como se dice en esa misma sentencia, siguiendo la línea sentada en la sentencia C-037 de 1996. Al interpretar que las normas en conflicto establecen principios limitados, la Corte trata de evitar el conflicto ajustando el alcance de los principios hasta el mayor grado de proximidad no conflictiva posible, en el cual fija el límite. Esta estrategia se emplea también en la sentencia C934 de 2006, acogiendo la ratio decidendi de la sentencia C-561 de 1996.

En una tercera etapa, que parece iniciarse con la sentencia C-545 de 2008, la Corte mantiene 
su estrategia de resolver el problema de la prevalencia en el plano hermenéutico, mediante una sentencia condicionada, en la cual declara exequible la ley procesal demandada, "en el entendido de que el legislador debe separar, dentro de la misma Corte Suprema de Justicia, las funciones de investigación y juzgamiento de los miembros del Congreso".

Sobre la base de la evidencia que suministra el análisis jurisprudencial precedente, no es posible sostener que la hipótesis $\mathrm{F}$ sea falsa. Lo mismo puede decirse de la hipótesis G. El desarrollo jurisprudencial en esta materia, que además de lo ya estudiado en el anterior asunto concreto, aparece, entre otras, en las siguientes sentencias: C-225 de 1995, C-802 de 2002 y C-067 de 2003, no es suficiente para inclinarse por alguna de las dos hipótesis alternativas, o para declinarlas del todo, lo que bien podría indicar que el problema de la prevalencia o bien es un falso y aparente problema, o es un problema real, pero tan terrible, que bien vale la pena evitarlo a toda costa, así sea acudiendo al rodeo hermenéutico.

\section{Más allá del plano normativo}

La estrategia seguida por la Corte es la de convertir el problema lógico en un problema hermenéutico. Su postura, planteada en la sentencia C-225 de 1995, y reiterada varias veces, es que el artículo 93 de la Carta debe ser interpretado según el único sentido razonable en que es posible hacerlo, a saber: los tratados "forman junto con el resto del texto constitucional un bloque de constitucionalidad". En este bloque todas las normas son constitucionales y gozan del mismo rango y jerarquía. Por ello, bien merece la pena estudiar esta postura como una hipótesis alternativa a las inicialmente planteadas. Esta podría ser la hipótesis $\mathrm{K}$.

Tanto la Constitución, como el bloque, obedecen a la lógica de los sistemas, de hecho el bloque es una herramienta sistemática que se emplea para hacer integraciones normativas. Por ello, no parece descabellado asumir que el problema lógico planteado lo es sólo en apariencia, pues en realidad se trata de un problema sistemático, cuya solución no sólo puede darse por la vía de la jerarquía, como si el asunto fuese tratado en una junta de positivistas, sino que admite un proceso de armonización hermenéutica. Esto invalidaría o falsearía las hipótesis $\mathrm{F}$ y G, pues ellas no podrían ser posibles por sustracción de materia, y brindaría un soporte de verosimilitud a la hipótesis $K$.

El punto de partida de la hipótesis $\mathrm{K}$ es la afirmación de la equivalencia de las normas en conflicto en cuanto a su rango y jerarquía, con lo cual se evita el riesgo de una solución por vía de autoridad o de prevalencia, y se posibilita una salida razonable, ponderada y armónica. Las alternativas hermenéuticas pueden ser, como lo hace la Corte, fijar límites a los principios que se desprenden de estas normas, para precaver que ellos choquen, en un ejercicio de ponderación, o quizá, como también podría hacerse, procurar interpretar cada norma en conflicto conforme al sentido de la otra, a fin de armonizarlas. Esta opción parece altamente viable, pues las normas contenidas en los tratados internacionales incorporados al bloque de constitucionalidad suelen consagrar contenidos mínimos para los derechos y las libertades fundamentales, a partir de los cuales es posible construir razonablemente una interpretación más o menos progresista de los mismos, aligerando de paso la carga de laconismo que la Carta, paradójicamente, suele tener en algunos asuntos. Es de lamentar que no exista todavía un grado suficiente de desarrollo jurisprudencial, como para poder analizar mejor esta hipótesis.

\section{El problema hermenéutico}

$$
\begin{array}{r}
\text { La inteligencia y el sentido común se abren } \\
\text { paso con pocos artificios. } \\
\text { Johann Wolfgang Goethe. }
\end{array}
$$

\section{La necesidad de una armonización}

Si el problema lógico, conforme a la hipótesis $\mathrm{K}$, no existe, por cuanto en el aparente conflicto sistémico subyace más bien un problema hermenéutico, pues se trata del conflicto entre 
normas que tienen un rango y jerarquía equivalentes, cuya armonización debe ser realizada por el juez mediante la herramienta de la interpretación, es menester ocuparse de este último. La verosimilitud de la hipótesis K afecta gravemente a la hipótesis $\mathrm{J}$, ya que si por medio de la interpretación jurisprudencial la Corte soluciona el problema hermenéutico, no es posible sostener que dicha interpretación carezca de valor.

Antes de proseguir con el análisis, es necesario precisar que en este documento no se hace referencia al valor del decisum de las sentencias proferidas por la Corte Constitucional, pues de hacerlo sería evidente que, en el caso de asuntos de constitucionalidad, ellas tienen valor normativo, ya que sus efectos son erga omnes, tema que siguiendo la estela de Kelsen (1997 y 2001), ha llevado a algunos estudiosos como Morelli (1997) a sostener que la Corte es un legislador complementario. Sobre tal base las hipótesis I y J no podrían siquiera ser planteadas, ya que sería evidente la verosimilitud de la hipótesis H. Tampoco se hace referencia a los obiter dicta de tales sentencias, por cuanto se trata de dichos de paso, o de consideraciones ocasionales, respecto de los cuales aparecerían en principio viables, con algo de amplitud dialéctica, todas las hipótesis, aunque en rigor, frente a ellos solamente puede tener sentido la hipótesis I. El análisis, como se indicó en la $\S 6$, se plantea respecto de la ratio decidendi, por cuanto en ella aparece la interpretación de la Corte que es relevante para resolver el caso, valga decir, la auténtica jurisprudencia.

\section{La doctrina constitucional}

Antes de pasar de lleno al estudio del valor de la jurisprudencia, entendida en los anteriores términos, es necesario definir la suerte de la hipótesis J. Para hacerlo no se requiere mayores digresiones, pues fundándose en la ratio decidendi la Corte ha establecido junto a la cosa juzgada explícita del decisum, una cosa juzgada implícita. Además ha considerado que tiene competencia para fijar los efectos de sus decisiones, que pueden ser incluso retroactivos, como aparece en las sentencias C-113 y C-039 de 2003, entre otras muchas. Para abundar en motivos, puede traerse a colación, así sea de manera general, las expresas e imperativas remisiones que a la ratio decidendi se hace en algunas sentencias, generalmente en las llamadas modulativas, de las que da cuenta con versación Martínez (2000), como ocurre, por ejemplo, con la sentencia C-836 de 2001.

La modulación del decisum de la sentencia a partir de la ratio decidendi suministra un magnífico apoyo para dilucidar la cuestión de su valor. De momento es evidente que la hipótesis J, que niega cualquier valor a la jurisprudencia, es falsa. Es menester, entonces, proseguir con el análisis y con el proceso de verificación respecto de las hipótesis H e I. En este punto del discurso el juicio parece inclinarse por la verosimilitud de la hipótesis H. No obstante, la hipótesis I cuenta con una importante carta que juega en su favor: el artículo 230 de la Constitución. Esta norma, analizada en el capítulo dedicado al estudio del problema normativo de si la Constitución es o no fuente de derecho, aparece de nuevo ahora, pues establece que la jurisprudencia, junto con la equidad y los principios generales del derecho y la doctrina son "criterios auxiliares de la actividad judicial".

Los estudios de López (1999, 2006 y 2007), Uprimny (2003) y Moreno (2002) dan cabal cuenta del origen, evolución e implicaciones en nuestra tradición jurídica, de la distorsión generada por el estrecho entendimiento del artículo 230. No obstante, vale la pena examinar el asunto a la luz de la jurisprudencia constitucional, como ha sido habitual en este ensayo, para desarrollar el proceso de verificación de las hipótesis, tarea que se emprenderá a continuación.

La sentencia C-037 de 1996, por medio de la cual la Corte ejerció un control previo de constitucionalidad sobre el proyecto de ley estatutaria de la administración de justicia, al estudiar el artículo 5, relativo a la independencia y autonomía de la rama judicial, tema estrechamente 
vinculado con el artículo 230 de la Constitución, y por esa vía con la hipótesis I, es un referente revelador en este asunto.

En dicha sentencia, la Corte empieza precisando la noción de "ley", para aclarar que ella debe entenderse en su sentido general, ya que ella comprende, en primer lugar, a la Constitución Política. De otra parte, la Corte, sobre la base de las sentencias C-083 y T-123 de 1995, habla de la "doctrina constitucional", la cual en determinados casos puede tener efectos vinculantes. La "doctrina constitucional" no es la jurisprudencia, pues esta noción hace referencia a una cualificación adicional, que a falta de ley, hace el intérprete autorizado de la Constitución. Con todo, prosigue la Corte, la doctrina constitucional "es un instrumento orientador, mas no obligatorio, como sí ocurre cuando se emplea como elemento integrador: porque en este caso, se reitera, es la propia Constitución -ley suprema-, la que se aplica”.

La doctrina probable es una especie de categoría intermedia entre las hipótesis I e $\mathrm{H}$. Verifica la hipótesis I, pues se distingue de la jurisprudencia $\mathrm{y}$, además, es un instrumento orientador no obligatorio. Verifica la hipótesis $\mathrm{H}$, ya que cuando se emplea como elemento integrador, ella tiene valor normativo, tanto como lo tiene la propia Constitución. Si la doctrina probable fuese el único referente relevante para verificar las hipótesis, sería menester reformularlas para decir que la hipótesis I es la regla y la hipótesis $\mathrm{H}$ la excepción. No obstante, la jurisprudencia no se detendrá aquí.

\section{El precedente}

Con posterioridad a la sentencia C-037 de 1996, la Corte producirá un abundante número de sentencias en las que comenzará, desarrollará y profundizará su discurso sobre los precedentes judiciales. La historia de los precedentes en la jurisprudencia de la Corte Constitucional aparece relatada en la sentencia C-252 de 2001. Sus orígenes se remontan al debate que se dio al interior de la Corte en torno del valor normativo de la jurisprudencia. El debate enfrentó a la corriente "tradicional", de estirpe formal y positivista, cultora de la ley, próxima a la hipótesis I, con la corriente "renovadora", impulsada por los "nuevos aires" de la Constitución de 1991, cercana a la hipótesis $\mathrm{H}$.

La postura tradicional consideraba que la jurisprudencia sólo es relevante, como fuente supletoria, en tres casos: cuando la norma tiene un significado oscuro, cuando existe una contradicción, es decir un problema lógico o de coherencia, y cuando existen "problemas de plenitud del orden normativo", es decir, de falta de una respuesta normativa clara frente al caso. El debate, que empezó en el seno de la Corte Constitucional, pronto se extendió a toda la judicatura, al punto de que si bien el asunto parece superado en la propia Corte, sigue siendo disputado tanto en el interior de otras Cortes, como en las relaciones de éstas con la Corte Constitucional.

La doctrina constitucional, materia analizada en la sección anterior, fue el primer paso visible en el camino que acabaría alejando a la Corte de la hipótesis I y aproximándola a la hipótesis $\mathrm{H}$. Esto ocurre en el año de 1995, con las sentencias C-083 y T-123. Esta última, pionera en esta historia, anuncia uno de los principales soportes argumentativos de la Corte para plantear la teoría del precedente: el principio de igualdad en la aplicación de la ley.

El segundo paso: el desarrollo de una "teoría fuerte en materia de precedentes", se fue dando con las sentencias C-037 de 1996, T-175 y C447 de 1997, SU-640 de 1998, SU-047 y SU-168 de 1999, T-009 y T-068 de 2000, hasta llegar a la sentencia C-252 de 2001. El tercer paso: la consolidación de la teoría fuerte de precedentes, se da con la sentencia T-569 de 2001 en la cual la Corte sostiene: "En la medida en que la ratio decidendi constituye una norma, en los términos indicados en el fundamento jurídico 3 de esta decisión, necesariamente adquiere alcance general, pues es obligatoria su aplicación en todos 
los casos que se subsuman dentro de la hipótesis prevista por la regla judicial".

\section{Las líneas jurisprudenciales}

Con lo analizado hasta aquí, existe evidencia suficiente para sostener que la hipótesis I es falsa $\mathrm{y}$, correlativamente, que la hipótesis $\mathrm{H}$ es verosímil. No obstante, el interesante desarrollo jurisprudencial de la teoría del precedente, amerita que el análisis prosiga, a fin de comprender en su integridad la línea jurisprudencial.

Algunos estudios como los de López (2007), Vallejo (2002) y Moreno (2002), reconocen en la sentencia C-836, dictada en el crucial año de 2001, el papel de punto de quiebre en la jurisprudencia de la Corte Constitucional sobre precedentes. Si bien, en rigor, ese papel le corresponde más adecuadamente a la sentencia T-569 de 2001, como se indicó atrás. La condición de ser una sentencia de constitucionalidad, cuya decisión tiene efectos erga omnes, y en cuyo decisum se incluye, como se dijo, a la ratio decidendi, le dio a la sentencia C-836 mayor trascendencia en la comunidad jurídica.

La sentencia C-1064 de 2001 es un interesante referente didáctico, pues en ella es posible ver en un caso concreto, relacionado con el tema del poder adquisitivo del dinero, cómo la Corte maneja tanto las normas constitucionales y legales tradicionales, como las nuevas normas de sus precedentes. En la sentencia SU-1300 de 2001, la Corte se ocupará de realizar un proceso de decantación de la teoría, precisando los conceptos de valor normativo y de valor ilustrativo, atribuyendo el primero al precedente: la ratio decidendi y el segundo a los dichos de paso o incidentales: los obiter dicta. Así, pues, la falseada hipótesis I acabará siendo adecuada a estos últimos. El proceso de decantación proseguirá con la sentencia T-1022 de 2002, en la cual se reiterará que la aplicación del precedente está condicionada a la verificación de una "plena identidad entre los hechos contenidos en la decisión anterior y los del caso en concreto".
La fuerza normativa de la jurisprudencia, valga decir, del precedente es tal, que la Corte Constitucional ha establecido, como lo reitera en el auto A-330 de 2006, al decidir el incidente de nulidad promovido contra su sentencia T-1319 de 2005, que el desconocimiento o apartamiento injustificado del precedente, acarrea la nulidad de la decisión judicial. En este caso la Corte, luego de revisar los cargos y de reconstruir su línea jurisprudencial en la materia, decidió no anular la sentencia de tutela.

El proceso de decantación de la teoría, encuentra en la sentencia T-086 de 2007 una oportunidad propicia para, reiterando la jurisprudencia, a estas alturas suficientemente consolidada, definir el precedente, caracterizar su pertinencia, expresar los motivos que fundamentan su fuerza vinculante y concretar la carga argumentativa que debe satisfacerse para apartarse de él. Así, pues:

Para la Corte Constitucional el precedente, es aquel antecedente del conjunto de sentencias previas al caso que se habrá de resolver, que por su pertinencia para la resolución de un problema jurídico, debe considerar necesariamente un juez o una autoridad determinada, al momento de dictar sentencia.

(...) La pertinencia de un precedente, se predica de una sentencia previa, cuando: "(i) la ratio decidendi de la sentencia que se evalúa como precedente, presenta una regla judicial relacionada con el caso a resolver posteriormente; (ii) se trata de un problema jurídico semejante, o a una cuestión constitucional semejante y (iii) los hechos del caso o las normas juzgadas en la sentencia son semejantes o plantean un punto de derecho semejante al que se debe resolver posteriormente". (...) La fuerza vinculante del precedente en el ordenamiento jurídico colombiano, se explica entonces, al menos, por cuatro razones principales: (i) en virtud del principio de igualdad en la aplicación de la ley (artículo 13 C.P.), que exige tratar de manera igual situaciones sustancialmente iguales; (ii) por razones de seguridad jurídica, ya que las decisiones judiciales debe ser "razonablemente previsibles"; (iii) en atención a los principios de buena fe y de confianza legítima (artículo 84 C.P.), que demandan respetar las 
expectativas generadas por las reglas judiciales en la comunidad; $y$ finalmente, (iv) por razones de rigor judicial, en la medida en que es necesario un mínimo de coherencia en el sistema jurídico.

(...) Las autoridades judiciales pueden apartarse de los precedentes judiciales en atención a su autonomía y a su deber de valorar cada caso en particular, (i) cuando se demuestre que no se configuran los mismos supuestos fácticos que en el caso resuelto anteriormente, por lo que no resulta aplicable la providencia previa; o (ii) cuando se encuentren motivos suficientes para replantear la posición jurídica precisada en el precedente, que signifique precisamente, superar o revisar tal antecedente judicial. El primer caso, puede ocurrir cuando ante una situación similar, "se observa que los hechos determinantes no concuerdan con el supuesto de hecho". En esta situación el juez deberá: (a) tener en cuenta el precedente, y (b) presentar las distinciones que justifican que éste no sea aplicable en el caso concreto. Cuando lo que se pretende es superar el precedente, por modificación, cambio normativo, etc., el fallador deberá: (i) hacer referencia al precedente que abandona, por lo que no puede simplemente omitirlo y (ii) ofrecer una carga argumentativa seria que explique de manera suficiente y razonada los motivos por los cuales considera que es necesario cambiar su propia jurisprudencia o modificarla en sus aspectos determinantes.

\section{Conclusiones}

Todas las teorias son legítimas y ninguna tiene importancia. Lo que importa es lo que se hace con ellas. Jorge Luis Borges.

El proceso de verificación, a la luz de la jurisprudencia de la Corte Constitucional, de las hipótesis planteadas en la sección 6, para responder las cuestiones que corresponden a los problemas jurídicos estructurales de la Constitución, enunciados en la sección 5 , ha permitido obtener unos resultados sólidos, de los cuales se pasará a dar cuenta enseguida en términos generales y en términos particulares.

En términos generales, en este documento se plantearon cuatro problemas jurídicos, a los cuales inicialmente correspondieron diez hipótesis de respuesta. En medio del proceso de verificación se hizo necesario plantear una hipótesis más en razón de las circunstancias. Frente al problema normativo, se verificó que la hipótesis A es falsa y que la hipótesis B es verosímil. Respecto del problema epistemológico se pudo constatar la falsedad de las hipótesis $\mathrm{C}$ y D, y la verosimilitud de la hipótesis E. El problema lógico tuvo la particularidad de exigir un replanteamiento de las hipótesis, por lo que fue necesario plantear aquí una nueva, la hipótesis $\mathrm{K}$, la que se constató como verosímil, mientras que las hipótesis $\mathrm{F}$ y G, inicialmente planteadas, resultaron falsas. En cuanto al problema hermenéutico, la evidencia demostró que las hipótesis I y J eran falsas, apareciendo como verosímil la hipótesis $\mathrm{H}$.

La Constitución Política es una verdadera norma jurídica (hipótesis B). La Constitución es fuente principal del derecho para todos los operadores jurídicos.

La Constitución Política es una norma abierta, cuyo contenido no está completamente determinado en un texto, ni es determinable a priori (hipótesis E). Las normas constitucionales tienen tres fuentes: el propio texto de la Constitución, los tratados internacionales que se incorporan, según lo amerite cada caso concreto, al bloque de constitucionalidad, y la persona humana.

Todas las normas constitucionales, independientemente su fuente, tienen el mismo rango $\mathrm{y}$ jerarquía (hipótesis K). Ellas prevalecen frente a todas las demás fuentes, pues gozan de supremacía dentro del sistema jurídico. De ello se siguen tres consecuencias: fundamentación y validez, interpretación y armonización, y aplicación preferente. Las normas constitucionales son el fundamento de todas las demás normas en el sistema jurídico, las cuales serán validas sí y sólo sí, no contravienen sus mandatos; son, también, un referente ineludible para la interpretación de todas las normas del sistema, que siempre deben armonizarse con los mandatos superiores; y, finalmente, son de aplicación preferente en caso 
de entrar en conflicto con cualquier otra norma que haga parte del sistema.

La jurisprudencia, entendida como la ratio decidendi de las decisiones judiciales, tiene valor normativo (hipótesis $\mathrm{H}$ ). La jurisprudencia es fuente principal de derecho, pues si se dan los presupuestos fácticos y de pertinencia, el operador judicial está obligado a considerar la jurisprudencia precedente. Los obiter dicta tienen valor ilustrativo, por lo que son fuente auxiliar del derecho.

\section{Referencias}

Arango, R. (2005) El concepto de derechos sociales fundamentales. Bogotá : Legis.

Bidart, G. J. (1995) El derecho de la Constitución y su fuerza normativa. Buenos Aires: Ediar, Sociedad Anónima Editora Comercial, Industrial y Financiera.

Bobbio, N. (1992). Teoría general del derecho, Bogotá D.C.: Temis.

Bobbio, N. (2001). El problema del positivismo jurídico. México: Fontanera.

Chinchilla, T. (1999) ¿Qué son y cuáles son los derechos fundamentales? Bogotá D.C.: Temis.

De Otto, I. (1999) Derecho Constitucional, Sistema de Fuentes. Barcelona: Ariel Derecho.

Dworkin, R. (1995) Los derechos en serio. Barcelona: Ariel.

Echeverri, A. (2006). La Constitución de 1991 y el principio de la seguridad jurídica. Revista de la Academia Colombiana de Jurisprudencia, 332, 29-36.

Fajardo L. A. (2007). Contenido y alcance jurisprudencial del bloque de constitucionalidad en Colombia. Revista Civilizar, 13, 15-34.
Gény, F. (1925) Método de interpretación y fuentes del derecho privado positivo. Madrid: Reus.

Hart, H.L.A. (1961) El concepto de derecho. Buenos Aires: Abeledo Perrot.

Ihering, R. Von (1954). El fin en el derecho. Puebla, México: Cajica.

Ihering, R. Von (1962). La lucha por el derecho. Buenos Aires: Atlantida.

Josserand, L. (1982) Del abuso del derecho y otros ensayos. Bogotá D.C.: Temis.+

Kelsen, H. (1997) Teoría Pura del Derecho. México: Porrúa.

Kelsen, H. (2001) Introducción a la teoría pura del derecho. Lima: Unam.

López, D. E. (1999) El valor del precedente constitucional en Derecho constitucional: perspectivas críticas. Bogotá D.C.: Siglo del Hombre.

López, D. E. (2004). Teoría Impura del Derecho. Bogotá D.C.: Universidad de los Andes, Legis y Universidad Nacional.

López, D. E. (2006). Interpretación constitucional (2a ed.). Bogotá D.C.: Universidad Nacional de Colombia, y Escuela Judicial Rodrigo Lara Bonilla.

López, D. E. (2007). El Derecho de los Jueces. Obligatoriedad del precedente constitucional, análisis de sentencias y líneas jurisprudenciales y teoría del derecho judicial. Bogotá D.C.: Legis y Universidad de los Andes.

Martínez, A. (2000). Tipos de sentencias en el control constitucional de las leyes: la experiencia colombiana. Revista Estudios Socio-jurídicos, 2, 9-32. 
Martín-Retortillo, L. (2004) La Interconexión de los Ordenamientos Jurídicos y el Sistema de Fuentes del Derecho. Madrid: Civitas.

Morelli Rico, S. (1997) La Corte Constitucional: ¿Un legislador complementario? Bogotá: Instituto de Estudios Constitucionales Carlos Restrepo Piedrahita.

Moreno, L. J. (2002) ¿Hacia un sistema de precedentes? Bogotá D.C.: Revista de la Academia Colombiana de Jurisprudencia, número 320.

Moreno, L. J. (2004) Libertad y justicia constitucional. Bogotá D.C.: Revista de la Academia Colombiana de Jurisprudencia, número 327. pp 165-184 reseña libro homónimo de Sanín Restrepo, R. 2004 acj, 274 pags.

Popper, K. (1994) La lógica de la investigación científica. Madrid: Tecnos.

Pound, R. (1950) Las grandes tendencias del pensamiento jurídico. Barcelona: Ariel.

Romero, N. (2008) El bloque de constitucionalidad y su justificación dentro del derecho constitucional. Bogotá D.C.: Boletín del Instituto de Estudios Constitucionales de la Universidad Sergio Arboleda, número 14.
Ross, A. (2007) Teoría de las fuentes del derecho, Una contribución a la teoría del derecho positivo sobre la base de investigaciones histórico-dogmáticas. Madrid: Centro de Estudios Políticos y Constitucionales. Segunda reimpresión.

Recasens Siches, L. (1956) Nueva Filosofia de Interpretación del Derecho. México: Porrúa.

Sanín Restrepo, R. (2004) Libertad y justicia constitucional. Bogotá D.C.: Academia Colombiana de Jurisprudencia.

Uprimny, R. (2001) El bloque de constitucionalidad en Colombia. Un análisis jurisprudencial y un ensayo de sistematización doctrinal. Bogotá D.C.: Centro de Estudios de Derecho, Justicia y Sociedad. Recuperado de Internet de la http:/ /dejusticia.org/pdf/libros/ru_bloque Constitucionalidad.pdf el 2 de junio de 2008.

Uprimny, R. (2003) Interpretación judicial. En colaboración con Andrés Rodríguez Villabona. Bogotá D.C.: Escuela Judicial Rodrigo Lara Bonilla.

Vallejo García, F. (2002) La seriedad de los jueces. Bogotá D.C.: Revista de la Academia Colombiana de Jurisprudencia, número 320 . 
